\title{
Measures to Prevent and Combat Pear Scab (Venturia pirina) in the Climate Conditions of Lapusel
}

\author{
Lucia MIHALESCU ${ }^{1 *}$, Zorica VOȘGAN ${ }^{1}$, Oana MARE ROȘCA ${ }^{1}$, Monica MARIAN ${ }^{1}$, Stela JELEA ${ }^{1}$, Flavia \\ $\mathrm{POP}^{1}$, Anca DUMUT, ${ }^{1}$, Aurel MAXIM ${ }^{2}$, Mirela CORDEA ${ }^{2}$
}

${ }^{1}$ Technical University of Cluj-Napoca, North University Center of Baia Mare, Romania

${ }^{2}$ University of Agricultural Sciences and Veterninary Medicine, Cluj Napoca

* Corresponding author: luciamihalescu@yahoo.com

Bulletin UASVM series Agriculture 73(2)/2016

Print ISSN 1843-5246; Electronic ISSN 1843-5386

DOI 10.15835/buasvmcn-agr: 12414

\begin{abstract}
In this paper we studied the emergence and development of pear scab (Venturia pirina), as well as the combat methods, testing a couple of fungicides. The aim of the research has been to highlight the resistance, respectively the sensitivity of some pear varieties against the fungi attack, in order to make recommendations for the new plantations, as well as the testing of 7 fungicides, remarking the product with the highest biological effectiveness. The researches were conducted in the years 2013-2014 at the company SC Mecanochim Lapusel, Maramures County. The experiments were conducted on plots planted with the Olivier de Serres and Bergamotte Crassane varieties. The attack was calculated determining the attack frequency, intensity and degree. The linear-interrupted method was used, comprising 3 variants of 5 trees each. Analyzing the climate data, it has resulted that in 2013 scab had favourable development and attack conditions. The Olivier de Serres variety was noted for its resistance to fungus attack, with a frequency of $0.2-1.3 \%$ on fruits and insignificant frequency on leaves, for all 7 tested product variants. The Bergamotte Crassane variety was placed on the other end, with a higher frequency and intensity, both on fruits (2-3\%) and on leaves (2.5-3.5\%). The infections diminished in 2014 due to the unfavourable climatic conditions. Three products had better results, from the seven tested products, thus: Alcupral 50PU, Stroby DF and Chorus 50 WG.
\end{abstract}

Keywords: fungicides, scab, variant, warning.

\section{INTRODUCTION}

Pear, from the assortment of fruit trees, is highly important, being largely spread all over the country (Gradinaru and Istrate, 2009). The importance of the pear cultivation is due to the fruits nutritional, taste, therapeutic values. The fruits have specific technological qualities and high economic value (Zlati and Gradinaru, 2010). Pears consummation is recommended for the stimulation of red blood cell formation, toxins elimination; the leaves are used for kidney and bladder disorders, diabetes (Braniste and Parvan, 1986). The pear cultures have been affected by biotic and abiotic destructive factors, but the affected surfaces are gradually reduced due to the identification and combating measures (Stănica and Branişte, 2015). The protection activity is highly important, as the pathogenic agents should be prevented and combated (Mateescu, 2007). Scab is one of the damaging diseases due to Venturia pirina aggressive fungus, in favourable conditions for its development (Lefter and Minoiu, 1990).

\section{MATERIALS AND METHODS}

The experimental research was conducted in the years 2013-2014 at the company SC Mecanochim Lapusel, Maramures County. The experiments were conducted on plots planted with the Olivier de Serres and Bergamotte 


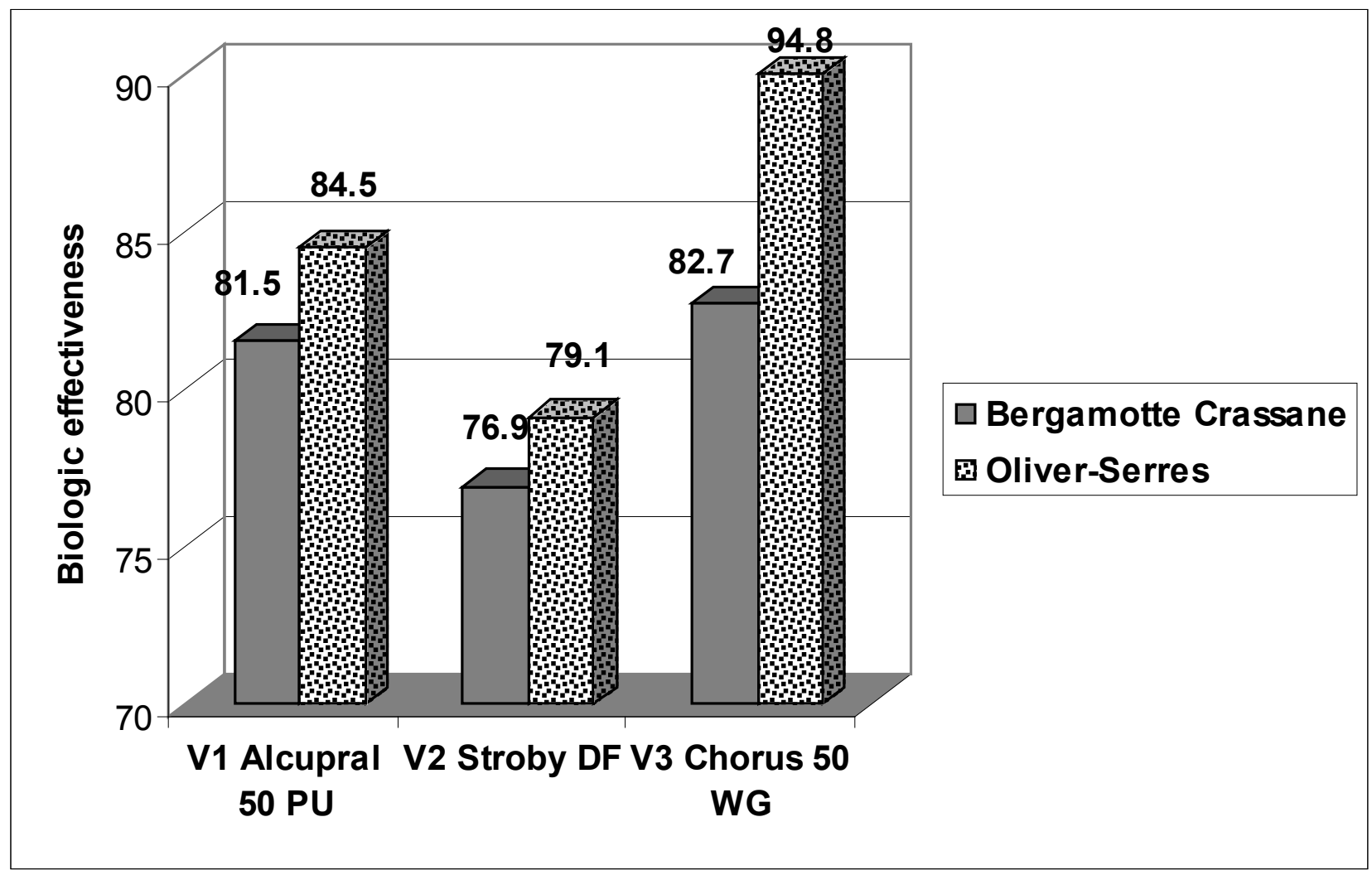

Fig.1. Biologic effectiveness of the three fungicides that were used in pear scab (Venturia pirina) combating, during 2013

Crassane varieties. The age of the plantation is 10 years; it is planted in intensive system, at a distance of $4 \times 2.5 \mathrm{~m}$. The climatic conditions were monitored using the AgroExpert electronic system, which it is necessary for setting up the chemical treatment. The linear-interrupted method was used, comprising of three replications. The attack was calculated determining the attack frequency, intensity and degree on the tree, leaves and fruits.

\section{RESULTS AND DISCUSSION}

We concluded, analyzing the climatic data of 2013, that scab had favorable development and attack conditions in the orchard with the experimental plot. The rainfalls of March were over the multiannual values (150 l/sqm), and the atmospheric humidity was over 70\% in April, May and June, with a high thermal background $\left(29^{\circ} \mathrm{C}\right.$ in April, $30.6^{\circ} \mathrm{C}$ in May), favorable conditions for fungus primary and secondary infections. The year of 2014 did not create optimum development and attack conditions, with less rainfalls and higher temperatures, mostly in the first part of the vegetation. Seven fungicides (Alcupral 50PU,
Triumf 40WG, Bravo 500SC, Delan 700WDG, Stroby DF, Chorus 50WG, Bellis) were tested during 2013, on the two studied varieties, Olivier de Serres and Bergamotte Crassane. For the Olivier de Serres variety, the attack on fruits and leaves was set within small limits, the frequency on fruits of $0.2-1.3 \%$; and on leaves both the frequency and the intensity were also set within small limits for all the 7 variants, due to the resistance against the action of fungus. The Bergamotte Crassane variety was situated on the other end, with a higher frequency and intensity both on fruits and leaves. The frequency of the attack on fruits was $2-3 \%$, and on leaves of $2.5-3.5 \%$.

Analyzing the data regarding the behaviour of the two varieties against the attack of scab, we have found that the infections diminished both on leaves and fruits, in 2014, due to the unfavourable climatic conditions. Three products, from the list of the seven tested products, proved better results, that is why they were chosen for the calculation of the biologic effectiveness, thus were set the products which would be recommended for scab combating. These were: Alcupral 50PU, 


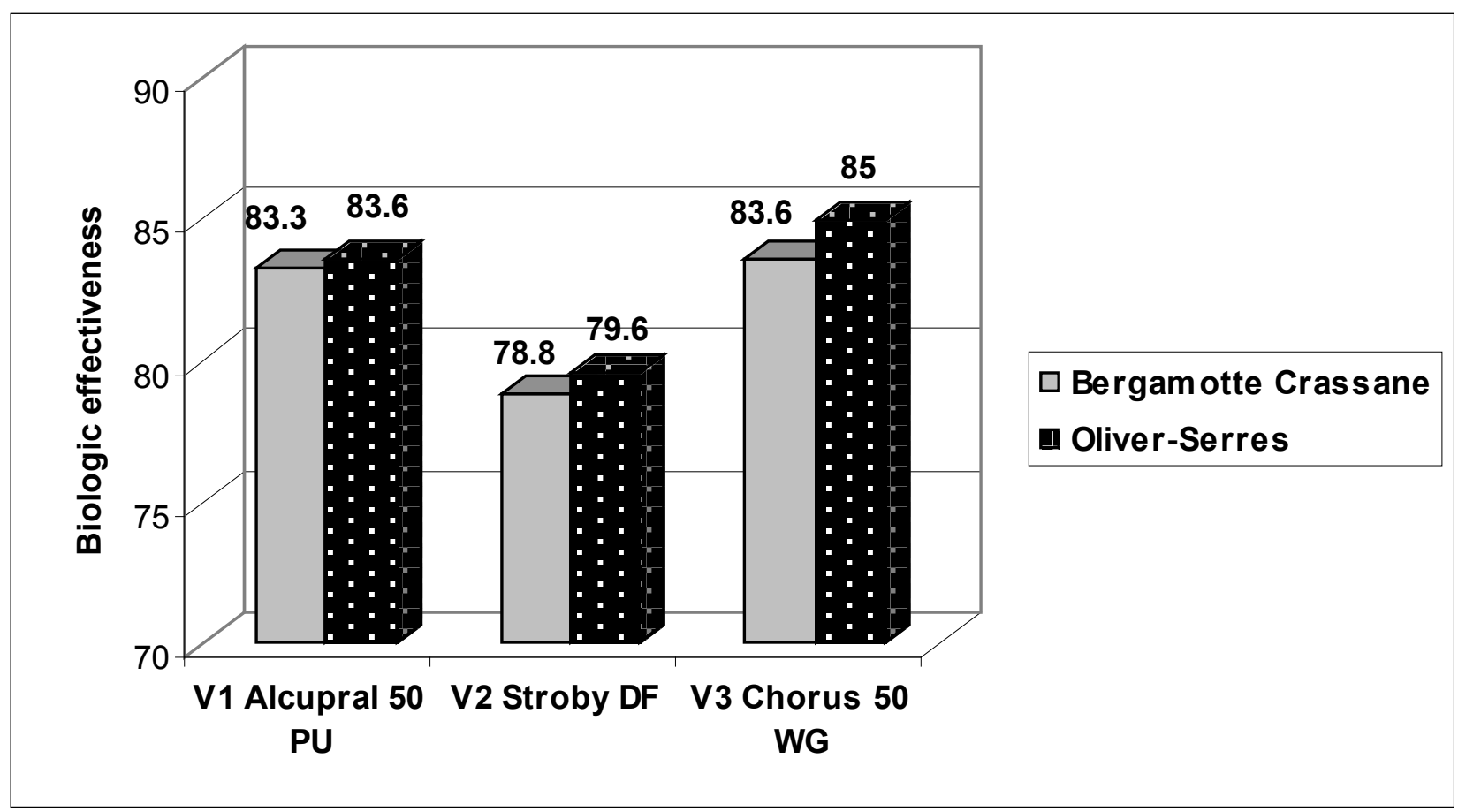

Fig.2. Biologic effectiveness of the three fungicides that were used in pear scab (Venturia pirina) combating, during 2014

Stroby DF, and Chorus 50WG. We found, from the experimental data, that all three variants had close values in the conditions of 2013, they being placed under the values of the untreated control, as this is shown in Figure 1.

We note, for the Bergamotte Crassane variety, a decrease of the attack intensity on leaves from $67.7 \%$ in case of the untreated control to $11.7 \%$, with the biologic effectiveness of $82.7 \%$ in case of Chorus 50WG. The biologic effectiveness, for the other two products, Alcupral 50PU, Stroby DF, is placed between 76.9 and $81.5 \%$, which are very good results, that is why the used products, in all three variants, are recommended to be used in the scab combating scheme. We note that, for the Olivier de Serres variety, the attack intensity on leaves had lower values, comparatively with the previous variety, due to its higher resistance against fungus; thus from $62.7 \%$ in case of the untreated control to $9.5 \%$, with a biologic effectiveness of $94.8 \%$ in case of the Chorus 50WG product. The biologic effectiveness was placed between 79.1 and $84.5 \%$ in case of the other two products that is why they are recommended to be used in the scab combating scheme.

The fungus development conditions were less favorable in 2014; the experimental data show that all three variants had close values, being placed under the value of the untreated control that could be observed in Fig. 2 .

We note, for the Bergamotte Crassane variety, a decrease of the attack intensity on leaves from $64.0 \%$ in case of the untreated control to $10.7 \%$, with the biologic effectiveness of $83.3 \%$ in case of Alcupral 50PU. The effectiveness was $78.8 \%$ in case of the Stroby DF product, and $83.6 \%$ in case of Chorus 50WG, with a diminished attack intensity of $10.8 \%$ versus the control, and it proved to be the most efficient product.

A decrease of the attack intensity on leaves, for the Oliver Serres variety, from $55 \%$ in case of the untreated control to $9 \%$, with the biologic effectiveness of $83.6 \%$, in case of the Alcupral $50 \mathrm{PU}$ product. The attack intensity, in case of Stroby DF, decreased versus the control to $11.2 \%$ and the biologic effectiveness was $79.6 \%$. Chorus $50 \mathrm{WG}$ proved to be the most efficient product, with the biologic effectiveness of $85 \%$.

\section{CONCLUSION}

Our research considered the data of the two varieties in order to underline the resistance of each one against the Venturia pirina fungus attack, with the purpose to make recommendations 
for the new established plantations with the higher resistant variety against this fungus. The most resistant variety against scab has been the Oliver Serres variety; and the most sensitive the Bergamotte Crassane variety.

Seven specific fungicides for scab combating were tested in relation to the untreated control. These products had been remarked with good results: Alcupral 50PU, Stroby DF, and Chorus 50WG. The results of this experiment are really useful for the fruit production, by setting up a prognosis as fair as possible and using the adequate fungicides, for example the Chorus $50 \mathrm{WG}$ product, which has the biologic effectiveness of up to $90.8 \%$, involving minimum spending and higher production.

\section{REFERENCES}

1. Braniste N, Parvan P (1986). Cultura parului. Edit. Ceres Bucuresti:7-10.

2. Gradinaru G, Istrate M (2009). Pomicultura generala si sociala. Edit. Tipo Moldova: 18.

3. Lefter G, Minoiu N (1990). Combaterea bolilor si daunatorilor speciilor pomicole semintoase. Ed. Ceres, Bucuresti.

4. Mateescu F (2007). Livada, gradina si via. Edit. M.A.S.T. București:71-72.

5. Stanică F, Branişte N (2015). Ghid pentru pomicultori. Editura Ceres Bucureşti:50-52.

6. Zlati C, Gradinaru G (2010). Pomologie. Ed.Tipo Moldova. 